\author{
Military Technical College \\ Kobry El-Kobbah, \\ Cairo, Egypt.
}

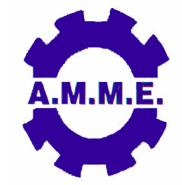

\title{
EXPERIMENTAL AND NUMERICAL INVESTIGATION OF MECHANICAL BEHAVIOR OF NOTCHED COMPOSITE LAMINATES
}

\author{
Y. Sami*, R. M. Gadelrab**, M. M. Abdel-Wahab* and Y. EL-Shaer*
}

\begin{abstract}
Existence of notches greatly affects the mechanical behavior and damage in composite laminates. In the present work, the effect of different parameters (hole sizes, number of layers and stacking sequences) on damage growth and failure of Glass/Polyester laminates containing central circular notches was investigated. Tests were performed on $\left[0^{\circ}\right],\left[0,90^{\circ}\right]$ and $\left[ \pm 45^{\circ}\right]$ notched specimens to investigate the effect of different parameters. The damage progression in the composite laminates during tests was monitored using optical non-destructive technique. The notched laminate failure strength was compared with the predicted strength from the semi-empirical point stress criterion (PSC). A finite element model was developed using ANSYS Parametric Design Language (APDL) to predict the notched strength and the damage growth during tensile loading taking into consideration the application of Hashin failure criterion and material stiffness degradation on the failed elements. The predicted notched strength and damage growth showed a good agreement with the experimental results obtained.
\end{abstract}

\section{KEY WORDS}

Composite material, Notched strength, Finite element, ANSYS Package.

* Egyptian Armed forces.

** Professor, Dept. of Mechanical Engineering, Jazan University, Jazan, Saudi Arabia. 


\section{INTRODUCTION}

Polymer matrix composites (PMC) have several advantages over metals and plastics such as high specific strength and stiffness, light weight, low cost and flexibility in design. Glass fiber reinforced plastics (GFRP) have high strength to weight ratio so its demand in many fields such as aircrafts structures has risen in recent years[1]. Since the composite material cannot be welded like metallic material, it is often subjected to geometric discontinuity for some functions such as bolted joints, electric wires and pipes. In order to have confidence on the composite component, a designer must have a good understanding of the effect of stress concentration raisers, such as notches, on the life and mechanical behavior of this component. The damage and failure mechanisms of a notched composite laminate due to loading become more complex than in an unnotched laminate due to the existence of the notch. The sensitivity of a composite laminate to notches is dependent on many factors such as notch size and geometry, laminate thickness, fiber orientation and machining quality. All these factors could change the damage growth during loading [2].

Early work in the field of notched composite laminates focused on developing analytical models for the prediction of notched strength. A comprehensive review of these is given by Awerbuch and Madhukar[3]. One of the earliest models was developed by Waddoups et al. [4], who applied a characteristic length to linear elastic fracture mechanics in order to predict notched strength with respect to notch size. Whitney and Nuismer [5] used a normal stress-based approach to develop two similar models, Point Stress Criteria(PSC) and Average Stress Criteria(ASC). These two models assume that notched laminate failure takes place when the stress at a certain critical distance or the average stress up to a critical distance reaches the unnotched strength.

The Damage Zone Model (DZM) introduced by Backlund [6] for notched composite laminates simulates damage development in the stress intense region at the edge of the notch and the numerical procedure of the DZM is based on the finite element method. Eriksson and Aronsson [7] developed a closed form solution called the Damage Zone Criterion(DZC) which is accurate as DZM and as simple as ASC and PSC. This model was based on the assumption that a homogeneous damage zone grows at the hole tip and perpendicular to the loading direction.

Kortschot and Beaumont [8] found that the damage before failure took the form of matrix cracking in the off-axis plies and axial splits in the $0^{\circ}$ plies. The axial splits have a great role in redistributing the stress and thus delay the failure.

Lagace [9] investigated the effect of stacking sequence and hole diameter upon the notched strength of a laminate while using a constant specimen width. Eh found that laminates with large amounts of delamination prior to failure showed non-linear stress-strain curves during loading. Liu [10] studied the matrix damage in transparent cross ply glass/polyester laminates with double edge semi-circular notches under increasing tensile loading. The experiments were done on different thicknesses and notch sizes. He found that the main fracture mechanisms were longitudinal splits, matrix cracking and delamination. 
In this study, an experimental program was done to investigate the effect of notch size, number of layers and ply orientation on the mechanical behavior of notched composite laminate. The notched strength results were compared to the predicted results from Point Stress Criterion (PSC). A finite element model was developed using ANSYS v12.0 to predict the notched strength and the damage growth during tensile loading. This finite element model has the ability to predict the failure strength for complex notched structures, in case of combined loading and for different notch shapes.

\section{EXPERIMENTAL WORK}

\section{Laminate Preparation}

The material used in this study was E-glass roving as reinforcement and Polyester as matrix as shown in Table 1. Thin wooden frames, shown in Fig. 1, having equispaced slots at each side were used to produce the required laminates. These frames were cut using a laser cut machine. The fiber bundles were laid between the slots of these frames in the required direction. A number of wooden frames are prepared according to the required number of layers since each frame will be used to produce two layers. Then, Polyester was added to the bundles and the excess resin was removed. After the required layers were prepared, a weight of about $25 \mathrm{~kg}$ was applied over a glass plate which was put onto the laminates to remove the existing air bubbles and to have equal laminate thickness.

Table 1. Reinforcement and resin used in this study.

\begin{tabular}{|c|c|}
\hline Material & \multicolumn{1}{c|}{ Type } \\
\hline Matrix & $\begin{array}{l}\text { Polyester resin + Methyl ethyl ketone Peroxide } \\
\text { hardener }(1 \% \text { of resin weight) }\end{array}$ \\
\hline Reinforcement & E-roving glass fiber (linear density $=2100 \mathrm{~g} / \mathrm{km})$ \\
\hline
\end{tabular}

The composite panel is removed from the wooden frames. A distance of about 20 $\mathrm{mm}$ from each side of the panel is removed and the composite panel is cut into the required configuration. Fiber volume fraction was determined by burning of the matrix in a muffle furnace according to ASTM D 3171 - 99[11] and it was found to be about $0.31 \%$.

\section{Unnotched Specimen Tests}

The first set of tests were the characterization tests to determine the elastic constants of the used laminate by performing tensile tests on a universal tensile test machine with a capacity of $250 \mathrm{kN}$ at a constant head displacement rate of 2 $\mathrm{mm} / \mathrm{min}$. The test machine is attached to a computer which continuously records the values of force and displacement. 
These tests were done on $\left[0^{\circ}\right],\left[9^{\circ}\right]$ to determine the Young modulus parallel and transverse to fiber direction according to ASTM D3039-99 [12] which were used as inputs to the finite element model. To determine the Poisson ratio, two perpendicular strain gauges were bonded to each specimen and a strainmeter was used to record the values from the two strain gauges during the test. Young's modulus was determined at $0.3 \%$ strain level as the ratio between stress and strain [12].

Tests were also done on [ \pm 45$]$ laminates to determine the shear modulus according to ASTM D3518-99 [13]. Two perpendicular strain gauges were also bonded to the specimen and the shear strain was calculated from the two perpendicular strains. The shear modulus was determined at $0.4 \%$ strain level [13].

\section{Notched Specimen Tests}

The second set of tests was aimed to determine the effect of different parameters on the notched specimen. When studying the effect of a certain parameter, specimens of $200 \times 25 \mathrm{~mm}^{2}$ were cut from the same composite panel in order to maintain the same manufacturing conditions to all specimens tested.

To investigate the effect of notch size, unidirectional specimens with centrally located hole of 2.5, 5, 7.5 and $10 \mathrm{~mm}$ diameter were produced. The specimen and the holes were cut using a laser cut machine. In order to investigate the effect of number of layers, unidirectional specimens with 2, 4 and 6 layers were cut with holes of $5 \mathrm{~mm}$ diameter. Finally, to investigate the effect of stacking sequence, composite panels of $\left[0^{\circ}\right],\left[0 / 90^{\circ}\right]$ and $\left[ \pm 45^{\circ}\right]$ fiber orientation were produced with holes of $5 \mathrm{~mm}$ diameter.

The damage growth during these tests was observed by using the back light technique [14] and many photos at different load levels were taken. The used backlight technique depends on the transparency of glass/polyester laminates. Placing a bright light source behind the laminate under test makes the damage appears in the form of shadows and some photos were captured using a digital camera at different load levels so damage progression can be observed. It was also possible to video the damage growth in real time.

\section{RESULTS}

\section{Unnotched Laminate Tests}

In case of $\left[0^{\circ}\right]$ specimens, the typical sequence of fracture modes leading to tensile failure in unidirectional laminate was: fiber breakage followed by edge delamination before final failure. This failure mode code can be written as DGM according to [12]. The first, second and third letters mean edge Delamination, within the Gage length, and near the specimen Middle, respectively. While in the case of $\left[90^{\circ}\right.$ ] specimens, the failure took place in the form of transverse matrix failure. This failure mode code can be written as LGM according to [12]. The first, second and third letters mean Lateral, within the Gage length, and near the specimen Middle, respectively.

Finally, in the case of $\left[ \pm 45^{\circ}\right]$ specimens, failure took place in the form of matrix cracking at $45^{\circ}$ from loading direction followed by fiber/matrix debonding and fiber 
failure at the peak load. The elastic constants which resulted from the characterization test are shown in Table 2 and they were compared with the results from mechanics of composite materials relations which predict the elastic constants [15]. The relative error ( $\left.\frac{\text { Experimental results }}{\text { Theoretical results }}-1\right)$ was also tabulated.

Table 2. Results from characterization tests.

\begin{tabular}{|l|c|c|c|}
\hline \multicolumn{1}{|c|}{ Property } & Experimental & Theoretical & Error (\%) \\
\hline $\mathrm{E}_{11}$, Young's modulus in fiber direction [GPa] & 22 & 23.8 & -7.5 \\
\hline $\begin{array}{l}\mathrm{E}_{22}, \text { Young's modulus transverse to fiber } \\
\text { direction [GPa] }\end{array}$ & 6 & 5.58 & 7.5 \\
\hline $\mathrm{U}_{12}$, Poisson's ratio & 0.3 & 0.32 & -6.25 \\
\hline $\mathrm{G}_{12}$,Shear modulus [GPa] & 1.8 & 2.1 & -14.3 \\
\hline
\end{tabular}

\section{Notched Laminate Tests}

The effect of notch size on the strength ratio (notched to unnotched strength) is shown in Fig. 2. The notched strength decreases by increasing the notch size because in case of smaller hole the high stressed region is more localized than in the case of larger hole. So, in the latter case there is a larger volume subjected to high normal stresses. Hence, the failure strength decreases in the case of large holes.

The results obtained from the experimental work were compared to the values from the Point Stress Criterion (PSC). In order to apply the PSC, it is required to determine the unnotched strength and the characteristic distance. The unnotched strength was determined experimentally using specimens free from notches. The characteristic distance could be determined from any hole diameter and then it was used to predict the notched strength for any hole diameters. It was found that the characteristic distance was not dependent on the hole diameter and it was approximately constant if it was calculated from different hole diameter. The characteristic distance was found to be $0.57 \mathrm{~mm}$.

During the test, a number of photos were captured in order to study the damage growth until failure. The damage initiation starts with longitudinal cracks (splits) in the loading direction at the notch tip. These cracks were accompanied by small delamination area at the notch tip. By increasing the tensile load these splits continued to increase in length in the longitudinal direction. Final failure took place by matrix failure, fiber matrix debonding and edge delamination, as shown in Fig.3 for different load levels.

The effect of number of layers on the strength ratio is shown in Fig. 4. The notched strength decreases by increasing the number of layers. The reason is that in the case of thinner laminates the longitudinal cracks (splits) play a greater role on relieving and redistributing the local stresses at the notch tip and hence increasing the value of the notched strength. In the case of thicker laminates it was found that the axial splits were limited to the outer or boundary layers and hence less stress 
redistribution would be made [16]. It was also noted that the length of axial splits prior to failure in thick laminates was less than that for thin laminates. Hence, less stress redistribution would happen and lower notched strength value.

It was shown from experiments that the unidirectional laminate has the highest notched strength because it has the maximum number of layers oriented in the loading direction while the $\left[0 / 90^{\circ}\right]$ laminate has notched strength higher than the $\left[ \pm 45^{\circ}\right]$ laminate. The results obtained from the previous tests are shown in Table 3 . Note that any tabulated notched strength values were the average of four results for each group of tested parameter.

Table 3. Average notched strength as obtained from tensile tests.

\begin{tabular}{|c|c|c|}
\hline \multicolumn{2}{|c|}{ Parameter } & $\begin{array}{c}\text { Notched strength } \\
{[\mathrm{MPa}]}\end{array}$ \\
\hline \multirow{3}{*}{$\begin{array}{c}\text { Hole diameter } \\
{[\mathrm{mm}]}\end{array}$} & 2.5 & 255 \\
\cline { 2 - 3 } & 5 & 200 \\
\cline { 2 - 3 } & 7.5 & 145 \\
\cline { 2 - 3 } & 10 & 125 \\
\hline \multirow{3}{*}{ Number of layers } & 2 & 220 \\
\cline { 2 - 3 } & 4 & 200 \\
\cline { 2 - 3 } & 6 & 180 \\
\hline \multirow{3}{*}{ Stacking sequence } & $0^{\circ}$ & 200 \\
\cline { 2 - 3 } & $\left(0 / 90^{\circ}\right)$ & 100 \\
\cline { 2 - 3 } & $\left( \pm 45^{\circ}\right)$ & 35 \\
\hline
\end{tabular}

\section{FINITE ELEMENT MODELLING}

A finite element model was developed using ANSYS v12.0 in order to predict the notched strength and the damage growth while increasing the tensile load. A specimen of $200 \times 25 \mathrm{~mm}^{2}$ with $\left[0^{\circ}\right.$ ] fiber orientation, 4 layers and $5 \mathrm{~mm}$ hole diameter was chosen to be modeled. A 3-D model was generated so that the damage growth in each layer could be displayed and the stiffness degradation of each element in each layer could be made individually.

The preprocessing steps include building of the model, applying the boundary conditions and applying the load. Each layer in the model was meshed separately with a local element coordinate system representing the orientation of this layer. Due to the symmetry of the specimen, only a quarter of the specimen was modeled and appropriate symmetry boundary conditions were applied at the symmetry planes. A surface force in the form of sequential pressure steps was applied to the edge area to represent the increasing tensile load.

In the post-processing steps, subroutines were included in order to check each element failure using Hashin failure criterion [17], apply of a degradation rule on the failed elements and plot the damage shape. The used Hashin criterion distinguishes 
between the three failures mechanisms: fiber failure, matrix failure and fiber matrix debonding.

The flow chart in Fig. 5 illustrates the different steps of the program. The scope of using degradation rules is to disable the ply from carrying a certain load. Thus, for each mode of failure there exists a corresponding degradation rule. The stiffness degradation took place according to the following [18]:

In case of fiber failure:

$\mathrm{E}_{11}=\mathrm{E}_{22}=\mathrm{E}_{33}=\mathrm{U}_{12}=\mathrm{U}_{23}=\mathrm{U}_{13}=\mathrm{G}_{12}=\mathrm{G}_{23}=\mathrm{G}_{13}=0$

In case of matrix failure:

$\mathrm{E}_{22}=\mathrm{U}_{12}=0$

In case of fiber matrix debonding:

$\mathrm{U}_{12}=\mathrm{G}_{12}=0$

In the previous degradation rule, the degradation factor $(\mathrm{K})$ was set to zero where:

New property value $=\mathrm{K}^{*}$ old property value.

To avoid numerical problems during the finite element solution, the degradation factor was not set to zero. In the present model, a degradation factor of 0.2 and 0.3 was tried but it was found that the damage growth is greatly retarded. On the other hand, a degradation factor of 0.1 worked well and speeded up the progressive damage procedure and it was introduced by Scaramuzzino [19]. The load was divided into 25 pressure steps, each being $10 \mathrm{MPa}$. Final failure took place when the damage in the $\left[0^{\circ}\right]$ layers reaches the outer edge of the model.

Fig. 6 illustrates the damage growth while increasing the tensile load. The damage growth was compared to the one from the photos captured during the tensile experiments in Fig. 7. The predicted notched strength from the finite element model was $180 \mathrm{MPa}$ while it was $200 \mathrm{MPa}$ from the experiments.

The model was also used in the case of $\left[0 / 90^{\circ}\right]$ laminates to predict the damage growth. It was found from the experiments that the failure mechanisms leading to failure were transverse matrix cracks in the $90^{\circ}$ layers which increased in intensity while increasing the load until the layer became approximately fully damaged. Then, longitudinal cracks (splits) appeared and propagated in the longitudinal direction in the $0^{\circ}$ layers until failure. So, the $\left[90^{\circ}\right]$ layers failed at earlier steps of loading and the $0^{\circ}$ layers became the only carrier of load then failure took place when the $0^{\circ}$ layers could not withstand the tensile load as shown in Fig.8. Final failure took place in the form of fiber breakage and fiber/matrix debonding at about $45^{\circ}$. The predicted notched strength from the model was $120 \mathrm{MPa}$ while it was $100 \mathrm{MPa}$ from experiments. The damage plot is shown in Fig. 9.

\section{CONCLUSION}

Basic laminate constants were determined experimentally and compared to theoretical values. Then the effect of different parameters on the notched strength was studied. It was found that the notched strength decreases by increasing the hole diameter because the stress concentration is more localized in case of smaller holes. The resulting notched strengths are generally in good agreement with the predicted 
results using the Point Stress Criteria. The notched strength of unidirectional laminates was found to decrease by increasing the number of layers. The damage zone in case of thick laminates was found to be limited to the outer layer. It was also found that the $\left[0^{\circ}\right]$ laminates had higher notched strength than the $\left[0 / 90^{\circ}\right]$ and $\left[ \pm 45^{\circ}\right]$ laminates.

The damage growth during the tests was observed using the backlight technique which depends on the transparency of the used composite laminates. In case of unidirectional laminates, the main failure mechanism was longitudinal splits which led to final failure. The $\left[0 / 90^{\circ}\right]$ laminates failed by transverse matrix cracks in $\left[90^{\circ}\right]$ layers then longitudinal splits in $\left[0^{\circ}\right]$ layers until failure took place.

A finite element model was generated using ANSYS Parametric Design Language (APDL) to predict the notched strength and the damage growth during loading. Hashin failure criterion was included in the code to distinguish between the different modes of failure. A stiffness degradation rule was also included in order to reduce the material stiffness of the failed elements according to the type of failure. Good agreement was generally observed between the results obtained from experiments and those of the finite element model.

\section{REFERENCES}

[1] Singh I, Bhatnagar N, Drilling-induced damage in uni-directional glass fiber reinforced plastic (UD-GFRP) composite laminates. Advanced manufacturing technology, 2006. 27: p. 877-882.

[2] Belmonte, Mange , Ogin, Characterization and modelling of the notched tensile fracture of woven quasi-isotropic GFRP laminates. Composite science and technology, 2001. 61: p. 585-597.

[3] Awerbuch J, Madhukar MS., Notched strength of composite laminates: predictions and experiments - a review. Reinforced Plastics and Composites, 1985. 4: p. 3-159.

[4] Waddoups ME, Eisenmann JR, Kaminski BE, Macroscopic fracture mechanics of advanced composite materials. Composite Material, 1971. 5: p. 446-54.

[5] Whitney JM, Nuismer RJ., Stress fracture criteria for laminated composites containing stress concentrations. Compositte Material, 1974. 8: p. 253-265.

[6] Backlund, J., Fracture Analysis of Notched Composites. Computers and Structures, 1981. 13: p. 145-154

[7] Eriksson, Aronsson Strength of tensile loaded graphite/epoxy laminates containing cracks, open and filled holes. Composite Material, 1990. 24: p. 456-482.

[8] Kortschot MT, Beaumont PWR, Damage mechanics of composite materials: I - measurements of damage and strength. Composites Science and Technology 1990. 39: p. 289-301.

[9] Lagace, PA. Notch sensitivity and stacking sequence of laminated composites. in Composite materials: testing and design. 1986. Philadelphia.

[10] C. LIU, J. STERK, A. NIJHOF, R. MARISSEN, Matrix-Dominated Damage in Notched Cross-Ply Composite Laminates: Experimental Observations. Applied Composite Materials 2002. 9: p. 155-168. 
[11] ASTM D 3171.Standard test method for Constituent Content of Composite Materials, in Annual book of ASTM standards. 1999.

[12] ASTM D 3039-99.Standard test method for tensile properties of polymer matrix composite materials, in Annual book of ASTM standards. 1999.

[13] ASTM D 3518-99.Standard test method for in-plane shear response of polymer matrix composite materials by tensile test of a $\pm 45^{\circ}$ Laminate., in Annual book of ASTM standards. 1999.

[14] R.M. O'Higgins, M.A. McCarthy, C.T. McCarthy, Comparison of open hole tension characteristics of high strength glass and carbon fibre-reinforced composite materials. Composites Science and Technology, 2008. 68: p. 2770-2778.

[15] K.Kaw, Mechanics of composite materials. second ed. 2006.

[16] Harris , Morris, Fracture Behavior of Thick, Laminated Graphite/Epoxy Composites. 1984, Virginia Polytechnic Institute: Virginia.

[17] Th. Kermanidis, G. Labeas, K.I. Tserpes and Sp. Pantelakis, Finite element modelling of damage accumulation in bolted composite joints under incremental tensile loading, in Computational Methods in Applied Sciences and Engineering. 2000: Barcelona.

[18] M.M. Shokrieh, L.B. Lessard, C. Poon. Three-dimensional progressive failure analysis of pin/bolt loaded composite laminates. in Bolted Joints in Polymeric Composites. 1996. Florence, Italy.

[19] Scaramuzzino, A. Riccio and F. Influence of damage onset and propagation on the tensile structural behavior of protruding composite joints. in $4^{\text {th }}$ GRACM Congress on Computational Mechanics. 2002. Patras.

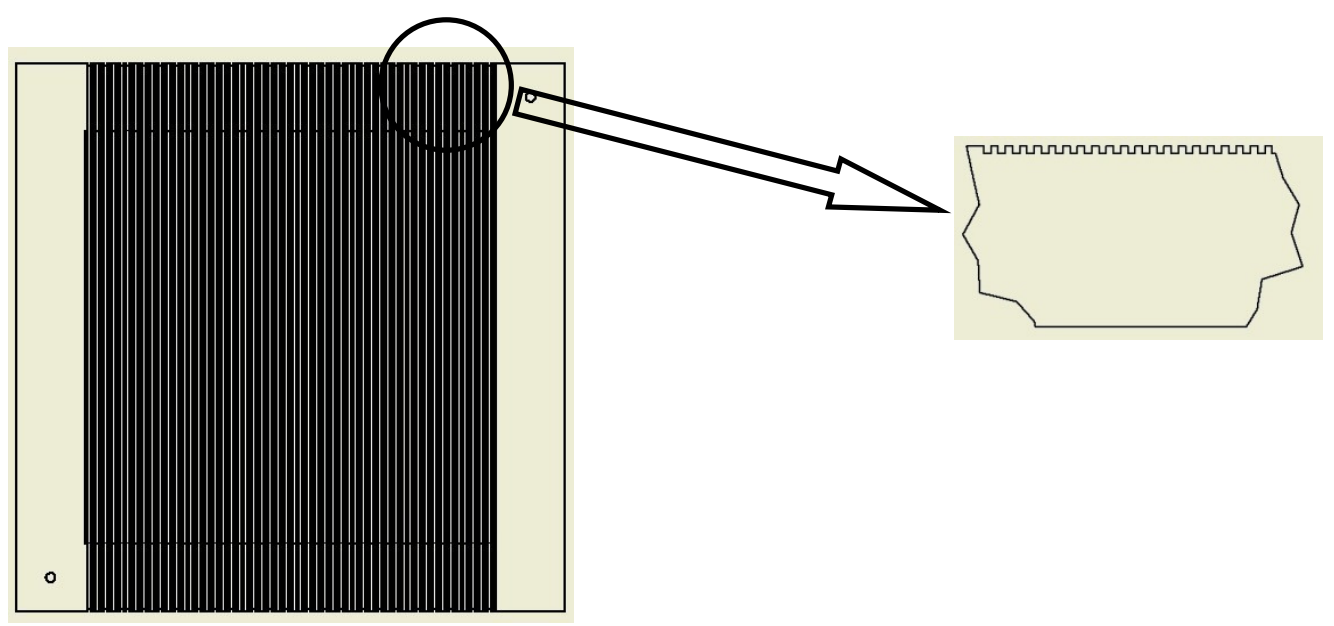

Fig. 1. Wooden frames for laminate production. 


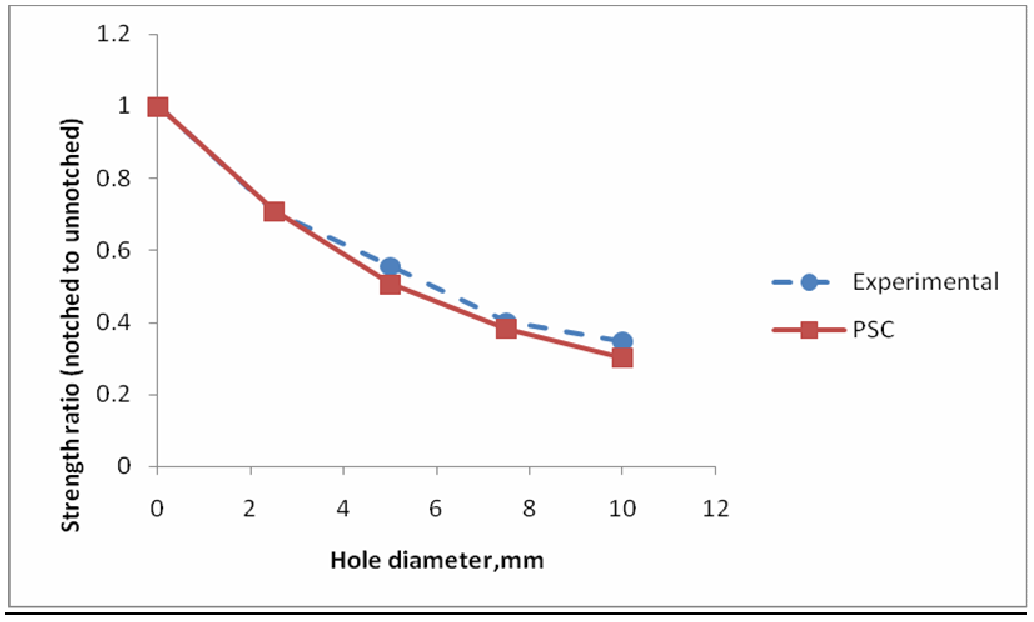

Fig. 2. Effect of hole diameter on notched strength.
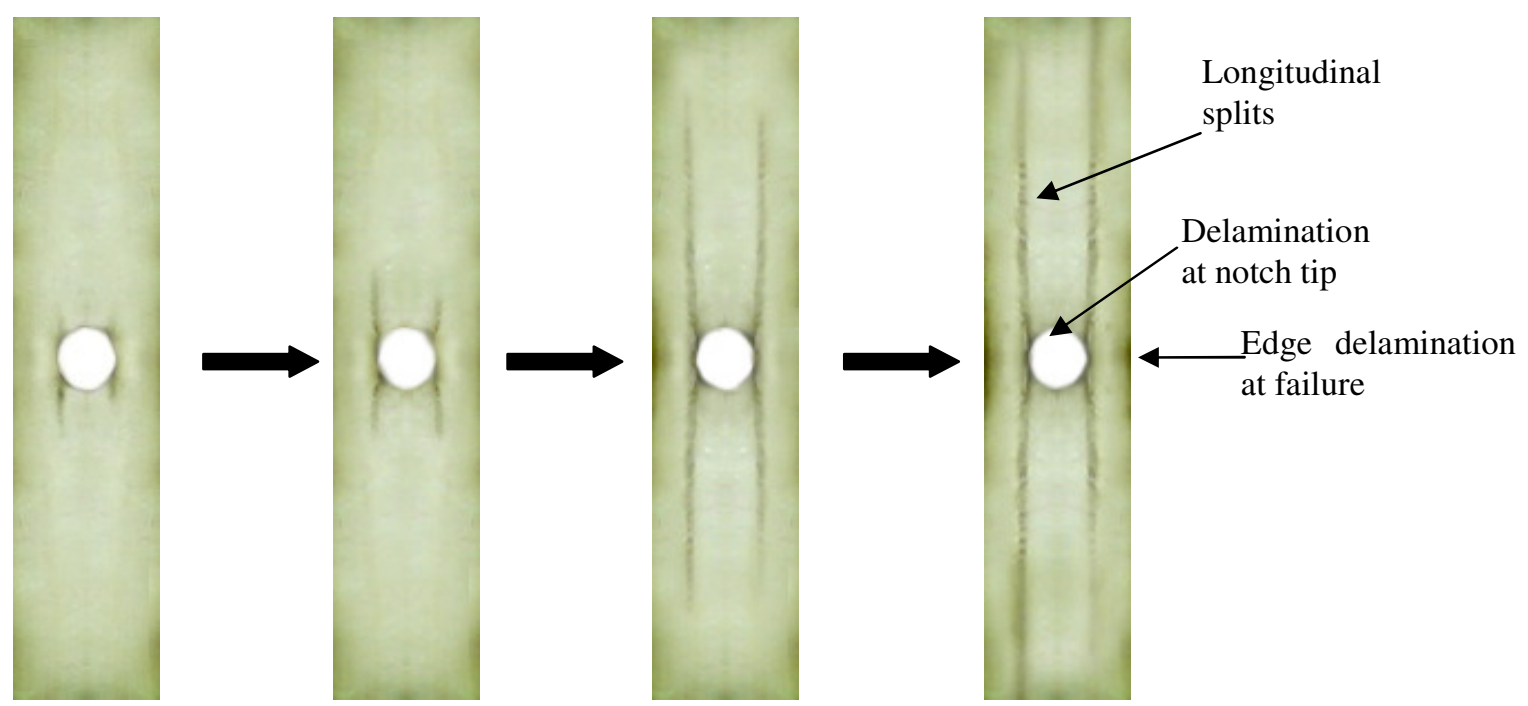

Fig. 3. Damage growth at different load levels.

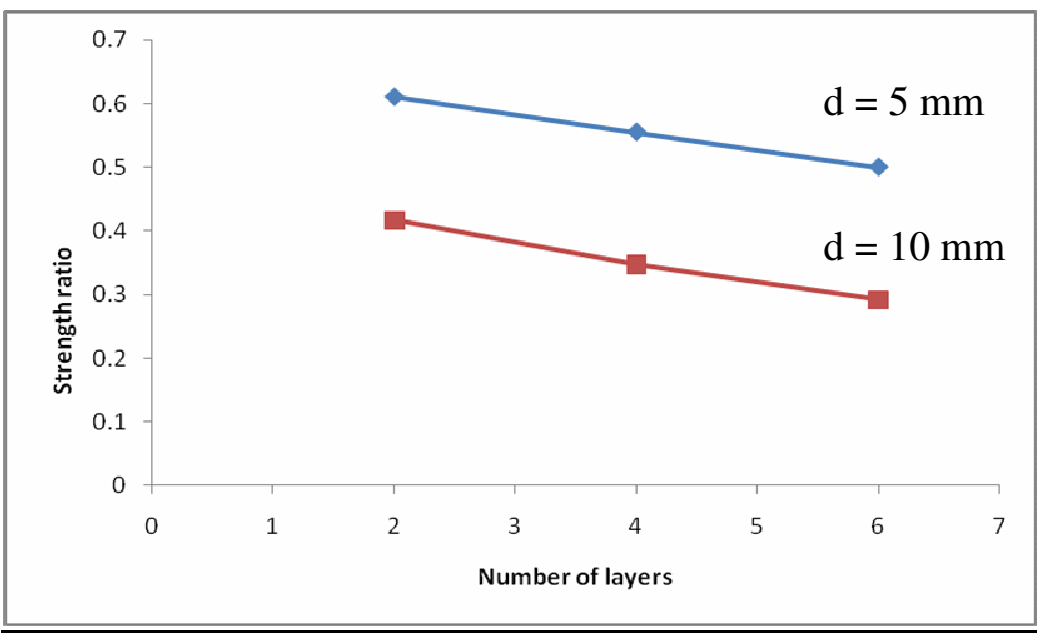

Fig. 4. Effect of number of layers on notched strength. 


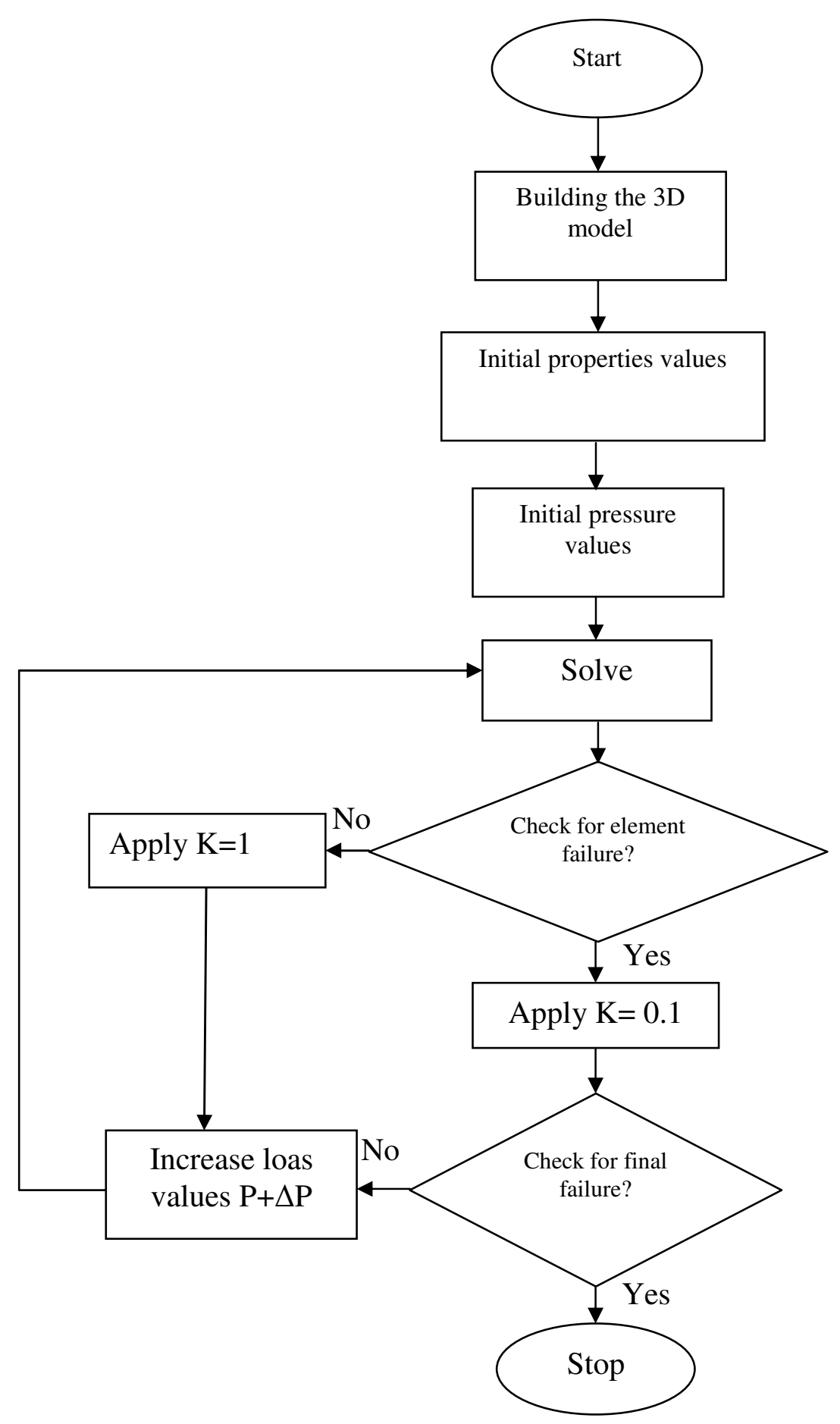

Fig. 5. Flowchart representing the finite element program. 


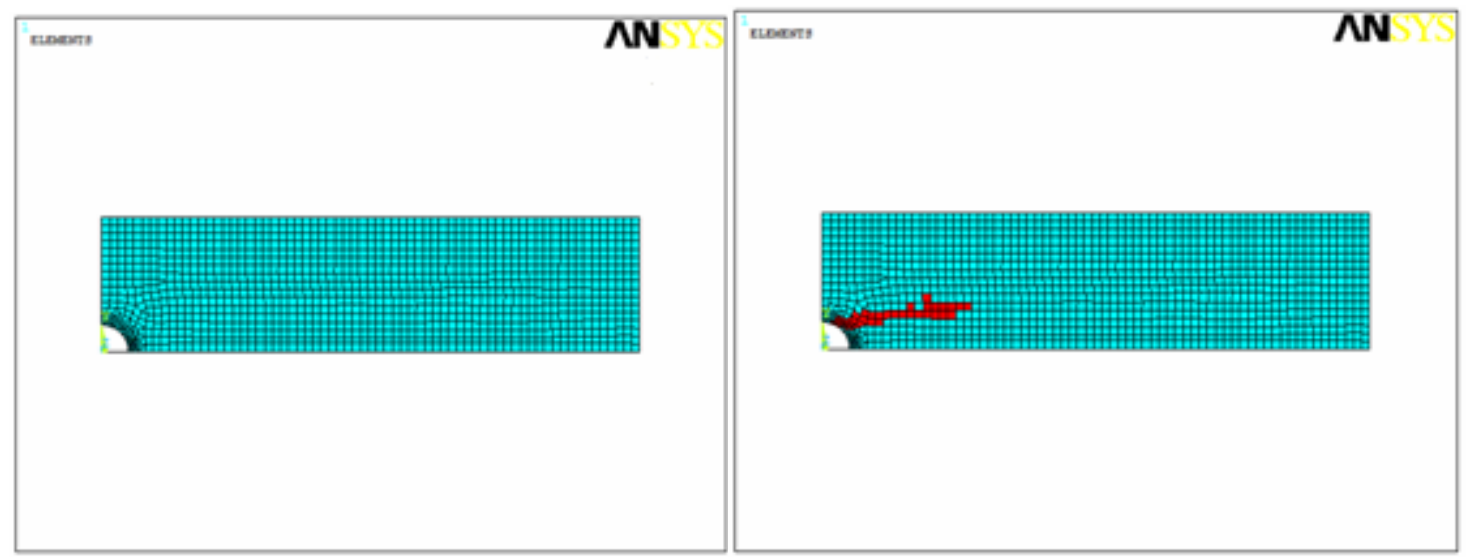

(a)

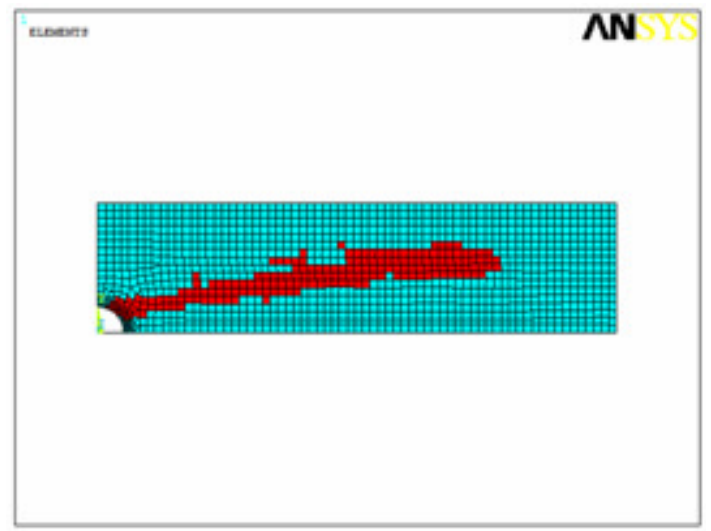

(c) (b)

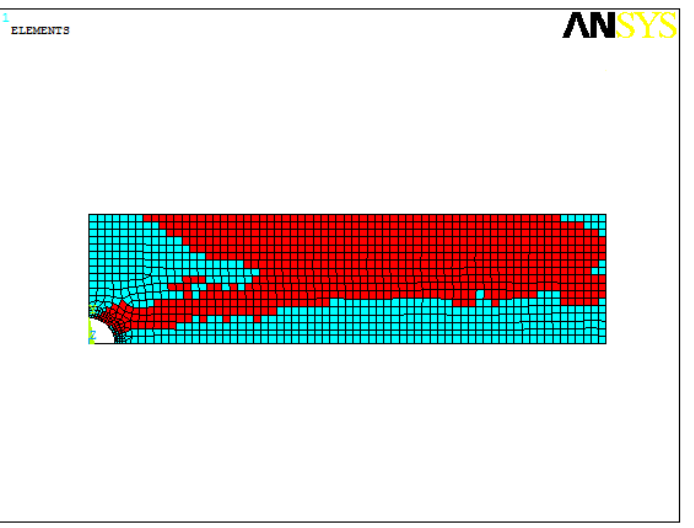

(d)

Fig. 6. Damage growth at different load steps: (a) initial loading. (b) at load step 12. (c) at load step 16. (d) at load step 18 and failure

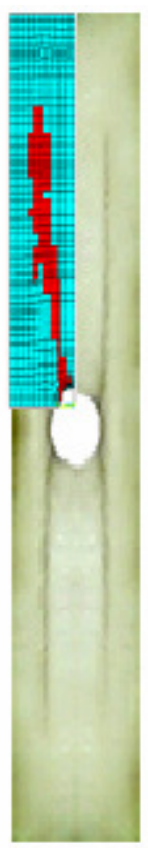

Fig. 7. Comparison between experimental (at $155 \mathrm{MPa}$ ) and FEM (at load step 16) results. 


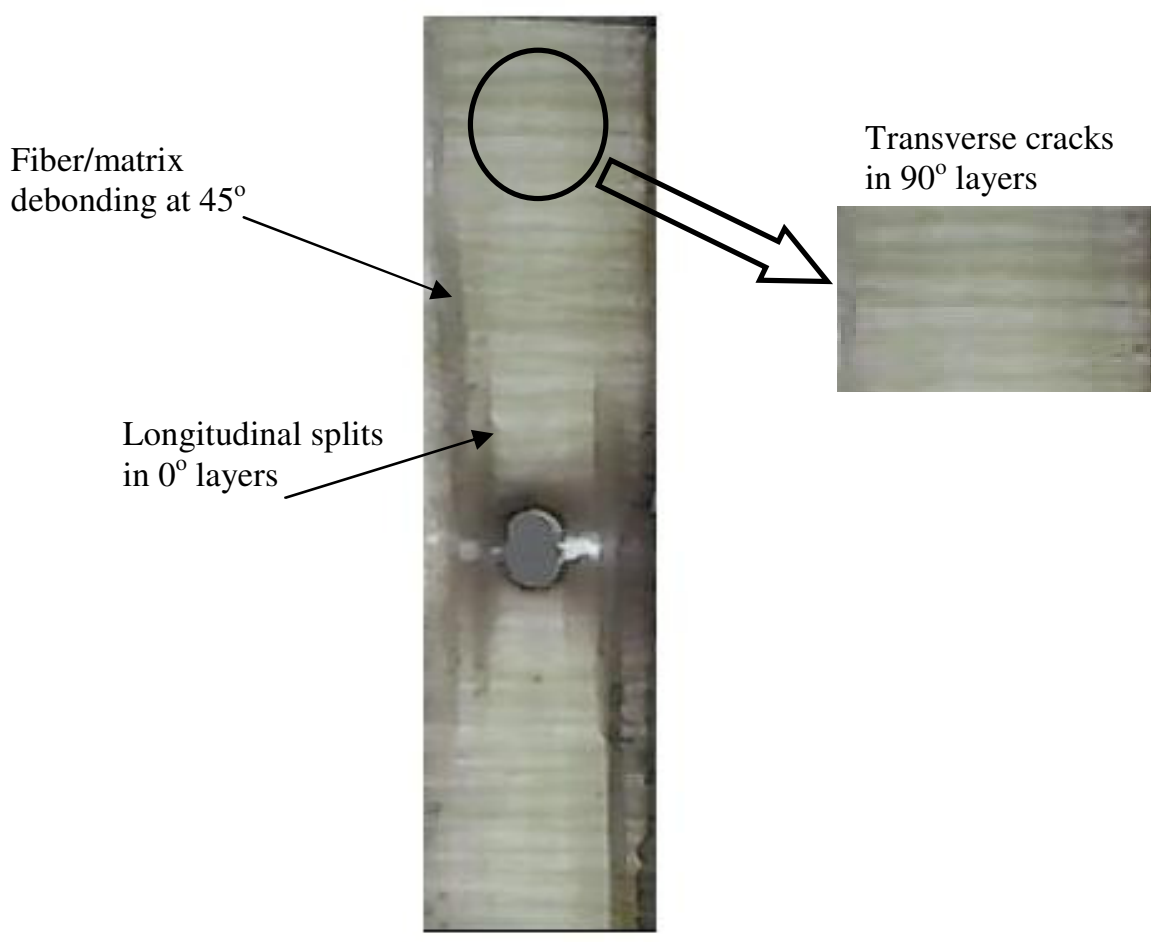

Fig. 8. Failure of $\left(0 / 90^{\circ}\right)$ laminate.

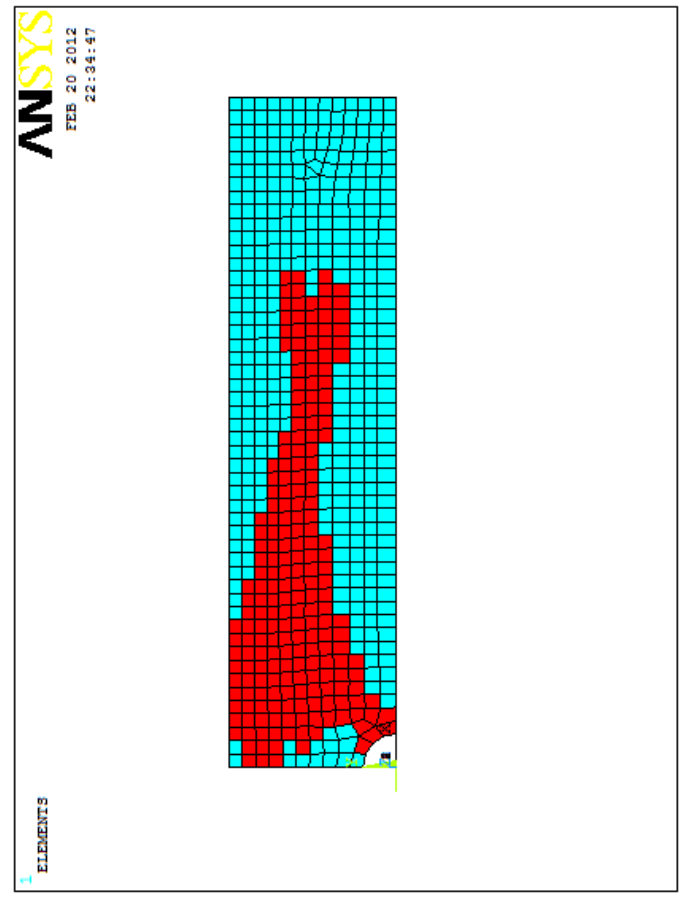

Fig. 9. Model of $\left[0 / 90^{\circ}\right]$ at failure. 